- Review Article

\title{
Overview of Physical Activity Counseling in Primary Care
}

\author{
Apichai Wattanapisit ${ }^{1,2, *}$, Sanhapan Wattanapisit ${ }^{3}$, Sunton Wongsiri ${ }^{4}$ \\ 'Department of Clinical Medicine, School of Medicine, Walailak University, Nakhon Si Thammarat, Thailand \\ ${ }^{2}$ Family Medicine Clinic, Walailak University Hospital, Nakhon Si Thammarat, Thailand \\ ${ }^{3}$ Department of Family Medicine, Thasala Hospital, Nakhon Si Thammarat, Thailand \\ ${ }^{4}$ Department of Orthopedic Surgery and Physical Medicine, Faculty of Medicine, Prince of Songkla University, Hat Yai, Thailand
}

Physical inactivity is a global health burden. Promoting physical activity in primary care through physical activity counseling is an effective intervention. This article provides an overview of and perspectives on physical activity counseling in primary care. The identification of physical inactivity as a health problem may increase the awareness of physical inactivity among patients and primary care providers, which will lead to an action plan. The contents of physical activity counseling should be based on evidence-based recommendations. Safety issues should be evaluated appropriately to optimize the utilization of primary care services. Physical activity counseling methods should be "tailored" for an individual using appropriate counseling methods and setting-specific resources. Multilevel barriers to physical activity counseling in primary care (i.e., healthcare providers, patients, and systems) must be addressed. Setting-specific strategies to overcome these barriers should be implemented to maximize the effectiveness of physical activity counseling in primary care.

Keywords: Counseling; Exercise; Physical Activity; Primary Health Care; Referral and Consultation

Received: September 19, 2019, Revised: October 3, 2019, Accepted: October 10, 2019

${ }^{*}$ Corresponding Author: Apichai Wattanapisit https://orcid.org/0000-0002-9537-8510

Tel: +66-8-6706-0440, Fax: +66-7567-2807, E-mail: apichai.wa@wu.ac.th 


\section{INTRODUCTION}

Physical inactivity or insufficient physical activity is a global health issue. According to the Global Burden of Disease Study 2017, physical inactivity caused more than 1 million deaths, and the mortality rate increased $22 \%$ compared with that documented in 2007. ${ }^{1)}$ Physical inactivity is also a proxy of deaths caused by major non-communicable diseases (NCDs) and cancers, such as ischemic heart disease, ischemic stroke, type-2 diabetes mellitus, as well as cancer of the colon, rectum, and breast. ${ }^{1)}$ The pandemic of physical inactivity contributes to billions of dollars in direct and indirect economic losses. ${ }^{2)}$ The World Health Organization launched the Global Action Plan on Physical Activity and Health 2018-2030, which aims to reduce global physical inactivity by $15 \%$ by $2030 .{ }^{3)}$ One of the policy actions is to incorporate physical activity into health services and social services. ${ }^{3)}$

Primary care systems have several effects on population health: better accessibility and quality of care; reduction in unnecessary specialty care; early management of health problems; health promotion; and disease prevention. ${ }^{4-6)}$ Recent studies have suggested that increasing the number of physicians in primary care can increase life expectancy and reduce the prevalence of death due to cardiovascular-, cancer-, and respiratory-related diseases in the population. ${ }^{7)}$ These specific characteristics of primary care provide opportunities to implement diverse healthcare services to improve the health of a population. Specifically, promoting physical activity in primary care is an effective approach to reducing physical inactivity among patients. ${ }^{8,9}$

Promoting physical activity in primary care can convert one out of 12 sedentary people to become physically active. ${ }^{8)}$ Compared with advice for smoking cessation, physical activity counseling (PAC) is a more efficacious intervention to change the behavior of patients. ${ }^{8,10)}$

"Physical activity" can be defined as any bodily movement produced by skeletal muscles that results in energy expenditure, which includes physical activity during work, traveling, and leisure time. ${ }^{11,12)}$ "Exercise" is a subset (and possibly an interchangeable term) of physical activity. ${ }^{11)}$ Therefore, "promoting exercise" is also a common term used in healthcare services. For example, "Exercise is medicine" is a well-known global campaign that encourages healthcare professionals to promote physical activity in their patients. ${ }^{13)}$ The concept of "exercise is medicine" has been recognized for centuries. ${ }^{14,15)}$ Using exercise to treat diseases is based on scientific evidence. ${ }^{16)}$

PAC is a component of promoting physical activity in primary care. Stoutenberg et al. ${ }^{17)}$ created a comprehensive three-step framework to promote physical activity: (1) assessment of physical activity; (2) PAC; and (3) referral to experts. Physicians in primary care can play an important part as counsellors in physical activity. ${ }^{18,19)}$ However, physician-, patient-, and system-based barriers to PAC in primary care have been documented. ${ }^{20-23)}$ Moreover, various primary care services contribute to different PAC practices. For example, PAC can be conducted solely by physicians or allied health professionals, or in combination.

A single standard of PAC practice in primary care is lacking. A "tailored" practice for a particular setting is necessary. This article pro- vides an overview of and perspectives on PAC in primary care.

\section{IDENTIFYING PHYSICAL INACTIVITY AS A HEALTH PROBLEM}

According to a global analysis from 2001 to 2016, the prevalence of physical inactivity was $27.5 \%$, and it was higher among high-income countries (36.8\%) than in low-income countries (16.2\%). ${ }^{24)}$ Physical inactivity is considered one of the determinants of health problems and can lead to chronic diseases. ${ }^{25}$ The elimination of physical inactivity can significantly lower the risk of all-cause mortality; ${ }^{26,27)}$ NCDs and cancers, ${ }^{28)}$ and cancer recurrence among cancer survivors. ${ }^{29,30)}$

"Physical inactivity" can be defined as "performing insufficient amounts of moderate- and vigorous-intensity activity" or "an insufficient physical activity level to meet present physical activity recommendations."31,32) Global recommendations on physical activity for health state that adults should participate in at least 150 minutes per week of moderate-intensity or at least 75 minutes per week of vigorous-intensity, or an equivalent combination of moderate- and vigorous-intensity aerobic physical activity. ${ }^{33,34)}$ Physical inactivity is generally considered based on the level of recommended aerobic physical activity. ${ }^{35-38)}$ However, several national-level surveys have also used the recommendation for muscle strengthening at least 2 days a week to measure physical activity. ${ }^{39-41)}$

In primary care, a recommended aerobic level is considered as a cut-off point between being "physically inactive" and "physically active." According to "exercise is medicine" guidelines, the "dose" of physical activity can be assessed based on two questions: (1) "on average, how many days per week do you engage in moderate-to-strenuous (vigorous) exercise?"; and (2) "on average, how many minutes do you engage in exercise at this level?"42) The result of these two screening questions provides the total minimum per week of an equivalent combination of moderate- and vigorous-intensity aerobic physical activity. One example can be a person who participates in 30 minutes per week of moderate-intensity and 30 minutes per week of vigorousintensity aerobic physical activity (1-minute energy expenditure of vigorous-intensity activity is equal to 2 minutes of moderate-intensity activity). Therefore, the total number of minutes per week is: $30+(30 \times 2)=90$ minutes per week of an equivalent combination of moderate- and vigorous-intensity aerobic physical activity, which would classify this person as "physically inactive."

Listing physical inactivity as a health problem could increase the awareness of primary care providers. Creating a list of active and current/previous diagnoses relevant to patient care ${ }^{43)}$ could encourage physicians to make decisions based on holistic concepts. ${ }^{44)}$ Electronic medical record (EMR) systems are used commonly in primary care. The incorporation of physical inactivity as an active health concern into the "problem list" of the EMR could aid the continuity of care among providers. This approach could help physicians to think holistically about their patients and to ensure that minor problems are less likely to be forgotten. Based on the International Statistical Classifica- 
tion of Diseases and Related Health Problems, 10th revision (2016), the code "Z72.3 Lack of physical exercise" can be used to identify physical inactivity. ${ }^{45}$

\section{ORGANIZING PHYSICAL ACTIVITY COUNSELING IN PRIMARY CARE}

PAC requires specific knowledge and skills. In addition, it should be tailored for each individual and each primary care setting. The sections below detail essential considerations to adapt for primary care. PAC for specific diseases is beyond the scope of this article.

\section{Recommendations on Physical Activity for Health}

A time-based recommendation for physical activity has been used widely. That is, 150 minutes per week of moderate-intensity or 75 minutes per week of vigorous-intensity aerobic physical activity is set as an indicator for "being physically active." This time-based indicator has been cited in research, ${ }^{37,38,46,47)}$ wearable devices, ${ }^{48,49)}$ public health, ${ }^{50-53)}$ and clinical services as well as in primary care ${ }^{54-56)}$ Kyu et al ${ }^{28)}$ detailed the dose-response effects of a higher level of physical activity on risk reduction of NCDs and cancers. Moreover, the global recommendations suggest physical activity for 2 or more days per week that strengthens the major muscle groups. ${ }^{33,34)}$ In addition, balance training for 3 or more days per week is recommended for people aged 65 years and above to prevent falls. ${ }^{33,34)}$

There are some changes in the recent guideline. The Physical Activity Guidelines for Americans (second edition) recommend that "adults should do at least 150 minutes to 300 minutes a week of moderate-intensity, or 75 minutes to 150 minutes a week of vigorous-intensity aerobic physical activity, or an equivalent combination of moderate- and vigorous-intensity aerobic activity." ${ }^{57)}$ They also recommend moderate- or greater-intensity of muscle-strengthening activities that involve all major muscle groups at least two days a week. ${ }^{57)}$

These guidelines also include recommendations for different age groups and health conditions. ${ }^{57)}$ Older adults should also include balance exercises. ${ }^{57)}$ Older adults who cannot undertake 150 minutes a week of moderate-intensity aerobic physical activity should be as active as their conditions and abilities allow. ${ }^{57)}$ Women, during pregnancy and the postpartum period, should do at least 150 minutes a week of moderate-intensity aerobic activity. ${ }^{57)}$ Individuals living with an illness or a specific condition may need the supervision of healthcare providers. For example, pregnant women have different contraindications to physical activity than that of the general population. ${ }^{58)}$

A step-based recommendation for physical activity is an alternative approach. Walking 10,000 steps every day is recommended to reduce health risks and improve metabolic outcomes. ${ }^{59,60)}$ For adults, walking 10,000 steps every day is equivalent to approximately $8 \mathrm{~km}$, can be achieved with an active lifestyle that includes walking for 30 minutes per day, and consumes 300-400 calories. ${ }^{59,60)}$ Walking can be categorized based on the number of steps walked per day: $5,000-7,400$ is "low active"; 7,500-9,999 is "somewhat active"; 10,000 or more is "active"; and more than 12,500 is "highly active." ${ }^{\text {(1) }}$ A walking pace or cadence threshold of 100 steps per minute (comparable with moderate-intensity physical activity) to 130 steps per minute (comparable with vigorous-intensity physical activity) is recommended among adults. ${ }^{62,63)}$

\section{Health Screening before Undertaking Physical Exercise}

Physical activity and exercise can increase injury risks, from musculoskeletal injuries to sudden cardiac arrest. ${ }^{64-66)}$ However, the prevalence of injury is low and most injuries are minor. ${ }^{67)}$ Studies have reported the incidence of exercise-related sudden cardiac arrest to range from 0.6 to 2.1 per 100,000 person-years. ${ }^{68-70)}$ Compared with the incidence of out-of-hospital cardiac arrest, the incidence is 65.4 per 100,000 person-years among Asian countries and 108.9 per 100,000 person-years in the Australia continent. ${ }^{71)}$ Accordingly, the incidence of exercise-related sudden cardiac arrest is relatively low. Studies have suggested that individuals with habitual physical activity carry a low risk of myocardial infarction and sudden cardiac death at baseline and during episodic physical activity. ${ }^{72,73)}$ This means that episodic heavy physical activity can increase the risk of serious cardiac events; however, regular physical activity can reduce the risk of those events in the longterm.

To avoid the risks of injuries and fatal cardiac events, health screening before undertaking physical exercise may be necessary for some people. A well-known preparticipation health-screening tool is the Physical Activity Readiness Questionnaire (PAR-Q) and You, which consists of seven simple questions to appraise one's ability to become more physically active. One or more positive answers on the PAR-Q requires that a physician be consulted for a physical activity clearance. ${ }^{74)}$ This approach can lead to an excessive number of physician visits. Physicians can use the Physical Activity Readiness Medical Examination (PARmed-X) to address medical concerns about participation in physical activity. ${ }^{74)}$

New tools based on evidence-based consensus are being developed to support the preparticipation screening for physical activity. ${ }^{75)}$ Physical Activity Readiness for Everyone (PAR-Q+) and the electronic Physical Activity Readiness Medical Examination (ePARmed-X+) can be used as self-screening tools and are applicable to people of all ages with or without chronic medical conditions. ${ }^{74)}$ These new tools could reduce the excessive number of physician visits for clearance for physical activity.

The preparticipation health-screening process set by the American College of Sports Medicine in 2015 is another example. This guideline aims to reduce the excessive number of physician referrals, while exercise is safe for most people. ${ }^{76)}$ The guideline provides a "decision tree" for health screening before exercise participation based on three factors: (1) the individual's current level of physical activity; (2) signs or symptoms and/or known cardiovascular, metabolic, or renal disease; and (3) desired exercise intensity. ${ }^{76,77)}$ A non-regular exerciser without cardiovascular, metabolic, or renal disease can start light- to moderateintensity exercise without medical clearance. ${ }^{76)}$ A person with symptomatic diseases may need medical clearance before participating in 
exercise ${ }^{76)}$ Regular exercisers (defined as three or more sessions per week of 30-minute moderate-intensity exercise) without signs, symptoms, or evidence of cardiovascular, metabolic or renal disease do not need medical clearance and can continue moderate- to vigorous-intensity exercise. ${ }^{76)}$ In addition, primary care providers must detect contraindications to physical activity and safety precautions for each individual. Further tests and specialist consultations may be required for some people with chronic or unstable conditions.

\section{Physical Activity Counseling Methods}

PAC methods vary according to theories, interventions, and providers. The term PAC is used interchangeably with "physical activity consultation." A systematic review on the content and competency of PAC by Breckon and colleagues revealed diverse theories and interventions, such as the transtheoretical model, social cognitive theory, brief negotiation, and motivational interviewing. ${ }^{78)}$

The 5As (Assess, Advise, Agree, Assist, and Arrange) framework is another commonly used method to counsel about physical activity. ${ }^{79,80)}$ This framework comprises the following: "Assess" physical activity levels; "Advise" on increasing physical activity; "Agree" on a tailored plan for physical activity; "Assist" to meet physical activity goals by providing pertinent strategies; and "Arrange" reminders and followups.

These processes require topic-based knowledge and communication skills. Primary care providers advise their patients to participate in physical activity based on the recommendations for physical activity, but 150 minutes per week of moderate-intensity aerobic physical activity is the general information provided. According to the transtheoretical model (stages of change), this information may be sufficient for a physically active person who is at the action or maintenance stage but must be translated and placed in an action plan for those in precontemplation, contemplation, or preparation stages. ${ }^{81)}$

The frequency, intensity, time, and type (FITT) principle is used widely for PAC ${ }^{82)}$ The challenge is to fulfill the content of each component.

Frequency represents the number of sessions of physical activity or exercise per week. According to the guidelines for adults, aerobic activities should be spread throughout the week so that at least 150-300 minutes per week of moderate-intensity physical activity is accumulated. ${ }^{57)} \mathrm{O}^{\prime}$ Donovan et al. ${ }^{83)}$ showed that participating in all leisuretime physical activity on one or two sessions per week may be sufficient to reduce the mortality risk. However, primary care providers can base their decisions on specific-age guidelines and personal readiness or abilities.

Intensity is the rate of energy expenditure (i.e., how hard a person works to carry out an activity). Most guidelines focus on moderate- to vigorous-intensity activity. The intensity of physical activity is vital for discussions of participation in physical activity. Nevertheless, this component is, sometimes, neglected by counselors. ${ }^{23)}$ There are several ways to identify the intensity of physical activity (Table 1). ${ }^{31,41,57,84,85)}$

Time refers to the duration of an activity session. Previously, the guidelines suggested a 10-minute bout of aerobic physical activity. ${ }^{33,34)}$ However, to achieve the weekly goal and health benefits, the recent guideline recommends that any duration of moderate- to vigorous-intensity physical activity can be accumulated as the total volume of physical activity. ${ }^{57)}$

The type of physical activity is defined by the characteristics and goals of the activity. Table 2 presents the major types of physical activity that should be acknowledged in primary care. ${ }^{57)}$

The FITT principle is emphasized to target the epidemic of physical inactivity. However, the enjoyment of individuals should be considered as an additional component to overwhelm the high prevalence of physical inactivity. ${ }^{86}$

\section{Follow-up and Referral Schemes}

In primary care, PAC can be conducted solely by physicians or allied

Table 1. Intensity of physical activity

\begin{tabular}{|c|c|c|c|c|}
\hline \multirow{2}{*}{ Intensity } & \multicolumn{3}{|r|}{ Aerobic activity } & \multirow{2}{*}{$\begin{array}{l}\text { Muscle-strengthening } \\
\text { activity }\end{array}$} \\
\hline & $\% H R_{\max }$ & Talk test (comfortable conversation) & Compendium of physical activities & \\
\hline Sedentary & $<50$ & Possible & $\begin{array}{l}\leq 1.5 \text { METs } \\
\text { - Sitting, playing traditional video game, computer game (1 MET) }\end{array}$ & \\
\hline Light & $50-63$ & Possible & $\begin{array}{l}<3 \text { METs } \\
\text { - Watering plants (2.5 METs) } \\
\text { - Walking to and from an outhouse (2.5 METs) }\end{array}$ & $40 \%-50 \%$ of $1 \mathrm{RM}$ \\
\hline Moderate & $64-76$ & Possible & $\begin{array}{l}\text { 3-5.9 METs } \\
\text { - Walking a dog (3 METs) } \\
\text { - Walking at } 3.5 \text { mph briskly on a firm surface (4.3 METs) }\end{array}$ & $60 \%-70 \%$ of $1 \mathrm{RM}$ \\
\hline Vigorous & $77-93$ & Not likely possible & $\begin{array}{l}\text { 6-8.8 METs } \\
\text { - Race walking ( } 6.5 \mathrm{METs}) \\
\text { - Walking at } 4.0 \mathrm{mph} \text { very briskly on a level, firm surface (6.8 METs) } \\
\text { - Jogging (general) (7.0 METs) }\end{array}$ & $\geq 80 \%$ of $1 \mathrm{RM}$ \\
\hline Very hard to maximum & $>93$ & Not possible & $\begin{array}{l}\geq 8.8 \text { METs } \\
\text { - Running a marathon (13.3 METs) }\end{array}$ & \\
\hline
\end{tabular}

The compendium of physical activities is a list of physical activities quantifying the energy cost as MET values (1 MET=3.5 mL/kg/min of oxygen uptake).

$\% \mathrm{HR}_{\max }$, percent of maximum heart rate $\left(\mathrm{HR}_{\max }=220\right.$-age); MET, metabolic equivalent; $1 \mathrm{RM}$, one-time repetition maximum (the heaviest weight a person can lift once). 
Table 2. Types of physical activity

\begin{tabular}{lc}
\hline \multicolumn{1}{c}{ Type } & \multicolumn{1}{c}{ Explanation } \\
\hline Aerobic activity & $\begin{array}{c}\text { Uses the large muscles for a sustained amount of } \\
\text { time to improve cardiorespiratory fitness (also } \\
\text { called "endurance" or "cardio activity"). } \\
\text { Increases the strength, power, endurance, and mass } \\
\text { Muscle-strengthening } \\
\text { activity }\end{array}$ \\
$\begin{array}{c}\text { Bone-strengthening activity } \\
\text { Creates a force on bones, which stimulates their } \\
\text { Balance activity }\end{array}$ & strength and growth. \\
$\begin{array}{l}\text { Improves the ability to resist forces that cause falls. } \\
\text { activity }\end{array}$ & Combines more than one type of physical activity \\
(i.e., aerobic, muscle-strengthening, and balance).
\end{tabular}

health professionals, or in combination. Physician-only counseling can be completed in a single consultation. Nonetheless, there is no guarantee that patients will change their behavior. A multidisciplinary approach could utilize the credibility of primary care physicians and their underlying relationship with their patients for PAC and offer referrals to allied health professionals for specialized management. ${ }^{87)}$ For example, nurse practitioners can administer physical activity screening, primary care physicians can counsel or write a physical activity prescription for the patient, exercise specialists can create an individualized plan, and behavioral counselors can follow up and refer the patient to local physical activity resources. ${ }^{54)}$

Moreover, exercise-referral schemes have been implemented to achieve higher yields on physical activity participation. In the United Kingdom, for example, exercise-referral schemes have been enacted in primary care since the 1990s for supervised exercise conducted in non-clinical environments or public leisure facilities. ${ }^{88,89)}$ Several factors must be considered when deciding an appropriate scheme in a particular setting of primary care. A systematic review and meta-analysis by Williams et al. ${ }^{89)}$ showed that exercise-referral schemes have a small effect on increasing physical activity in sedentary people (relative risk=1.20 and number needed to treat=17.2). Another systematic review showed that producing better health outcomes and higher adherence to physical activity required a scheme of longer duration (at least 20 weeks, compared with 8-12-week schemes). ${ }^{88)}$ In addition, the cost-effectiveness of exercise-referral schemes should be appraised. ${ }^{90}$

\section{BARRIERS TO PHYSICAL ACTIVITY COUNSELING}

\section{Healthcare Providers}

Lack of knowledge or training in PAC can be a barrier. Training in PAC is sparse in undergraduate medical education and postgraduate primary care training. ${ }^{47,91,92)}$ Other personal aspects can be barriers to physical activity; for example, unsuccessful efforts to change the behavior and attitude of patients (e.g., PAC is not a priority and lifestyle is a personal choice).$^{20)}$

\section{Patients}

Insufficient time, resources, and social support are regarded as patientbased barriers. ${ }^{54)}$ A low level of literacy and poor ability to understand information are limitations to PAC. ${ }^{23)}$ The patient's attitude regarding the importance and expectation of drug treatment rather than lifestyle modification can be a barrier to PAC..$^{20)}$

\section{Systemic}

Time constraints are a major barrier to PAC, as documented by studies in various settings. ${ }^{20,23)}$ Specifically, the duration of consultation in primary care varies from 48 seconds in Bangladesh to 22.5 minutes in Sweden. ${ }^{93)}$ Hence, the implementation of an appropriate proportion of PAC in the primary care consultation is difficult. Lack of protocols and financial incentive/reimbursement for PAC are systemic barriers. ${ }^{20,54)}$ Organizational barriers (e.g., discontinuation of primary care) can lead to failure in changing the behavior of the patient. ${ }^{23)}$ For example, a patient who does not see the same physician regularly may not connect with his/her previous PAC.

\section{APPROACHES TO OVERCOMING BARRIERS}

To overcome the barriers to PAC, different approaches in primary care are necessary. Primary care providers should be trained to counsel about physical activity. Training in physical activity is associated with greater confidence in discussing physical activity and exercise with patients. ${ }^{94)}$ One-day training as continuing professional development can increase the confidence, knowledge, and counseling behavior of physicians. ${ }^{95)}$

Communicating with patients to change their behavior is a challenging task. Primary care providers should give tailored information to patients. Writing a prescription for physical activity or exercise can improve and facilitate PAC and increase the levels of physical activity. ${ }^{96,97)}$ For patients with limited health literacy, primary care providers should focus on a communication strategy for each person, such as patient-centered communication, clear health communication, confirmation of understanding, and using communication technologies. ${ }^{98}$

At organizational and policy levels, primary care settings should focus on physical activity and healthy lifestyles as part of organizational culture. For example, the UK campaign "making every contact count" encourages healthcare providers to maximize the opportunity within routine healthcare interactions for a brief discussion on health and wellbeing. ${ }^{99)}$ Primary care settings can play a role as a health-promoting hub. In Korea, for example, the additional brief counseling after a periodic health examination is an effective intervention to increase physical activity. ${ }^{100)}$ An individual with a high health risk appraisal score is invited to receive the additional brief counseling led by a primary care physician. ${ }^{100)}$ Team-based care may help deal with a limited consultation time with the physician. A financial incentive for healthcare systems and healthcare providers to promote healthy lifestyles could help to lower the incidence of chronic diseases. ${ }^{101)}$ Most importantly, system-based interventions could overcome organizational barriers, such as assigning the patient to see a physician regularly. 


\section{CONCLUSION}

PAC in primary care is a practical intervention to deal with the pandemic of physical inactivity and NCDs. Physical inactivity should be addressed as a health problem to increase awareness among patients and primary care providers, which should lead to an action plan. PAC contents should be evidence-based and tailored for an individual using appropriate counseling methods and setting-specific resources. The primary care setting should identify the barriers to PAC (healthcare providers, patients, systemic). Moreover, strategies to overcome such barriers should be implemented.

\section{CONFLICT OF INTEREST}

No potential conflict of interest relevant to this article was reported.

\section{FUNDING}

This work was supported in part by the new strategic research (P2P) project within Walailak University, Thasala, Thailand.

\section{ACKNOWLEDGMENTS}

The authors thank Aekthawat Watthanachon and Atchara Aidwang for their support.

\section{ORCID}

Apichai Wattanapisit: https://orcid.org/0000-0002-9537-8510

Sanhapan Wattanapisit: https://orcid.org/0000-0002-4033-2726

Sunton Wongsiri: https://orcid.org/0000-0003-2921-9869

\section{REFERENCES}

1. GBD 2017 Risk Factor Collaborators. Global, regional, and national comparative risk assessment of 84 behavioural, environmental and occupational, and metabolic risks or clusters of risks for 195 countries and territories, 1990-2017: a systematic analysis for the Global Burden of Disease Study 2017. Lancet 2018;392:1923-94.

2. Ding D, Lawson KD, Kolbe-Alexander TL, Finkelstein EA, Katzmarzyk PT, van Mechelen W, et al. The economic burden of physical inactivity: a global analysis of major non-communicable diseases. Lancet 2016;388:1311-24.

3. World Health Organization. Global action plan on physical activity 2018-2030: more active people for a healthier world. Geneva: World Health Organization; 2018.

4. Starfield B, Shi L, Macinko J. Contribution of primary care to health systems and health. Milbank Q 2005;83:457-502.

5. Kroenke K. The many C's of primary care. J Gen Intern Med 2004;19: 708-9.

6. Valentijn PP, Schepman SM, Opheij W, Bruijnzeels MA. Understanding integrated care: a comprehensive conceptual framework based on the integrative functions of primary care. Int J Integr Care 2013;13: e010.

7. Basu S, Berkowitz SA, Phillips RL, Bitton A, Landon BE, Phillips RS. Association of primary care physician supply with population mortality in the United States, 2005-2015. JAMA Intern Med 2019;179: 506-14.

8. Orrow G, Kinmonth AL, Sanderson S, Sutton S. Effectiveness of physical activity promotion based in primary care: systematic review and meta-analysis of randomised controlled trials: version 2. BMJ 2012; 344:e1389.

9. Vuori IM, Lavie CJ, Blair SN. Physical activity promotion in the health care system. Mayo Clin Proc 2013;88:1446-61.

10. Stead LF, Buitrago D, Preciado N, Sanchez G, Hartmann-Boyce J, Lancaster T. Physician advice for smoking cessation. Cochrane Database Syst Rev 2013;2013:CD000165.

11. Caspersen CJ, Powell KE, Christenson GM. Physical activity, exercise, and physical fitness: definitions and distinctions for health-related research. Public Health Rep 1985;100:126-31.

12. World Health Organization. Global Physical Activity Questionnaire (GPAQ) analysis guide [Internet]. Geneva: World Health Organization [cited 2019 Jun 8]. Available from: http://www.who.int/ncds/ surveillance/steps/resources/GPAQ_Analysis_Guide.pdf.

13. Russell E. Exercise is medicine. CMAJ 2013;185:E526.

14. Sallis RE. Exercise is medicine and physicians need to prescribe it! $\mathrm{Br}$ J Sports Med 2009;43:3-4.

15. Tipton CM. The history of "exercise is medicine" in ancient civilizations. Adv Physiol Educ 2014;38:109-17.

16. Pedersen BK, Saltin B. Exercise as medicine: evidence for prescribing exercise as therapy in 26 different chronic diseases. Scand J Med Sci Sports 2015;25 Suppl 3:1-72.

17. Stoutenberg M, Galaviz KI, Lobelo F, Joy E, Heath GW, Hutber A, et al. A pragmatic application of the RE-AIM framework for evaluating the implementation of physical activity as a standard of care in health systems. Prev Chronic Dis 2018;15:E54.

18. King AC. Role of exercise counselling in health promotion. Br J Sports Med 2000;34:80-1.

19. Ribeiro MA, Martins Mde A, Carvalho CR. The role of physician counseling in improving adherence to physical activity among the general population. Sao Paulo Med J 2007;125:115-21.

20. Hébert ET, Caughy MO, Shuval K. Primary care providers' perceptions of physical activity counselling in a clinical setting: a systematic review. Br J Sports Med 2012;46:625-31.

21. Josyula LK, Lyle RM. Barriers in the implementation of a physical activity intervention in primary care settings: lessons learned. Health Promot Pract 2013;14:81-7.

22. Omura JD, Bellissimo MP, Watson KB, Loustalot F, Fulton JE, Carlson SA. Primary care providers' physical activity counseling and referral practices and barriers for cardiovascular disease prevention. Prev Med 2018;108:115-22.

23. Wattanapisit A, Thanamee S, Wongsiri S. Physical activity counselling among GPs: a qualitative study from Thailand. BMC Fam Pract 2019;20:72.

24. Guthold R, Stevens GA, Riley LM, Bull FC. Worldwide trends in insufficient physical activity from 2001 to 2016: a pooled analysis of 358 population-based surveys with 1.9 million participants. Lancet Glob 
Health 2018;6:e1077-86.

25. Gonzalez K, Fuentes J, Marquez JL. Physical inactivity, sedentary behavior and chronic diseases. Korean J Fam Med 2017;38:111-5.

26. Lear SA, Hu W, Rangarajan S, Gasevic D, Leong D, Iqbal R, et al. The effect of physical activity on mortality and cardiovascular disease in 130,000 people from 17 high-income, middle-income, and low-income countries: the PURE study. Lancet 2017;390:2643-54.

27. Samitz G, Egger M, Zwahlen M. Domains of physical activity and allcause mortality: systematic review and dose-response meta-analysis of cohort studies. Int J Epidemiol 2011;40:1382-400.

28. Kyu HH, Bachman VF, Alexander LT, Mumford JE, Afshin A, Estep K, et al. Physical activity and risk of breast cancer, colon cancer, diabetes, ischemic heart disease, and ischemic stroke events: systematic review and dose-response meta-analysis for the Global Burden of Disease Study 2013. BMJ 2016;354:i3857.

29. Loprinzi PD, Lee H. Rationale for promoting physical activity among cancer survivors: literature review and epidemiologic examination. Oncol Nurs Forum 2014;41:117-25.

30. Wattanapisit A. Physical activity for adult cancer survivors: a literature review. Walailak J Sci Tech 2017;14:1-10.

31. Tremblay MS, Aubert S, Barnes JD, Saunders TJ, Carson V, LatimerCheung AE, et al. Sedentary Behavior Research Network (SBRN): Terminology Consensus Project process and outcome. Int J Behav Nutr Phys Act 2017;14:75.

32. Van der Ploeg HP, Hillsdon M. Is sedentary behaviour just physical inactivity by another name? Int J Behav Nutr Phys Act 2017;14:142.

33. World Health Organization. Global recommendations on physical activity for health. Geneva: World Health Organization; 2010.

34. Wattanapisit A. A review of the current international physical activity guidelines for various age groups to prevent and control noncommunicable diseases. Songkla Med J 2016;34:39-49.

35. Dumith SC, Hallal PC, Reis RS, Kohl HW 3rd. Worldwide prevalence of physical inactivity and its association with human development index in 76 countries. Prev Med 2011;53:24-8.

36. Lee IM, Shiroma EJ, Lobelo F, Puska P, Blair SN, Katzmarzyk PT, et al. Effect of physical inactivity on major non-communicable diseases worldwide: an analysis of burden of disease and life expectancy. Lancet 2012;380:219-29.

37. Thanamee S, Pinyopornpanish K, Wattanapisit A, Suerungruang S, Thaikla K, Jiraporncharoen W, et al. A population-based survey on physical inactivity and leisure time physical activity among adults in Chiang Mai, Thailand, 2014. Arch Public Health 2017;75:41.

38. Wattanapisit A, Fungthongcharoen K, Saengow U, Vijitpongjinda S. Physical activity among medical students in Southern Thailand: a mixed methods study. BMJ Open 2016;6:e13479.

39. Bennie JA, De Cocker K, Teychenne MJ, Brown WJ, Biddle SJH. The epidemiology of aerobic physical activity and muscle-strengthening activity guideline adherence among 383,928U.S. adults. Int J Behav Nutr Phys Act 2019;16:34.

40. Bennie JA, Pedisic Z, van Uffelen JG, Gale J, Banting LK, Vergeer I, et al. The descriptive epidemiology of total physical activity, musclestrengthening exercises and sedentary behaviour among Australian adults: results from the National Nutrition and Physical Activity Survey. BMC Public Health 2016;16:73.

41. Yang YJ. An overview of current physical activity recommendations in primary care. Korean J Fam Med 2019;40:135-42.

42. American College of Sports Medicine. Exercise is medicine: healthcare providers' action guide [Internet]. Indianapolis (IN): American College of Sports Medicine [cited 2019 Jun 8]. Available from: http:// www.exerciseismedicine.org/support_page.php/provider-actionguide/.

43. Simons SM, Cillessen FH, Hazelzet JA. Determinants of a successful problem list to support the implementation of the problem-oriented medical record according to recent literature. BMC Med Inform Decis Mak 2016;16:102.

44. Van Vleck TT, Wilcox A, Stetson PD, Johnson SB, Elhadad N. Content and structure of clinical problem lists: a corpus analysis. AMIA Annu Symp Proc 2008;2008:753-7.

45. World Health Organization. International Statistical Classification of Diseases and Related Health Problems-10th revision. 5th ed. Geneva: World Health Organization; 2016.

46. Wattanapisit A, Vijitpongjinda S, Saengow U, Amaek W, Thanamee S, Petchuay P. Development of a physical activity monitoring tool for Thai medical schools: a protocol for a mixed methods study. BMJ Open 2017;7:e017297.

47. Wattanapisit A, Vijitpongjinda S, Saengow U, Amaek W, Thanamee S, Petchuay P. Results from the Medical School Physical Activity Report Card (MSPARC) for a Thai Medical School: a mixed methods study. BMC Med Educ 2018;18:288.

48. Henriksen A, Haugen Mikalsen M, Woldaregay AZ, Muzny M, Hartvigsen $\mathrm{G}$, Hopstock LA, et al. Using fitness trackers and smartwatches to measure physical activity in research: analysis of consumer wristworn wearables. J Med Internet Res 2018;20:e110.

49. Xie J, Wen D, Liang L, Jia Y, Gao L, Lei J. Evaluating the validity of current mainstream wearable devices in fitness tracking under various physical activities: comparative study. JMIR Mhealth Uhealth 2018;6: e94.

50. Fuzeki E, Banzer W. Physical activity recommendations for health and beyond in currently inactive populations. Int J Environ Res Public Health 2018;15:1042.

51. Kahlmeier S, Wijnhoven TM, Alpiger P, Schweizer C, Breda J, Martin BW. National physical activity recommendations: systematic overview and analysis of the situation in European countries. BMC Public Health 2015;15:133.

52. Weed M. Evidence for physical activity guidelines as a public health intervention: efficacy, effectiveness, and harm: a critical policy sciences approach. Health Psychol Behav Med 2016;4:56-69.

53. Oja P, Titze S. Physical activity recommendations for public health: development and policy context. EPMA J 2011;2:253-9.

54. AuYoung M, Linke SE, Pagoto S, Buman MP, Craft LL, Richardson $\mathrm{CR}$, et al. Integrating physical activity in primary care practice. Am J Med 2016;129:1022-9.

55. Courtney-Long EA, Stevens AC, Carroll DD, Griffin-Blake S, Omura JD, Carlson SA. Primary care providers' level of preparedness for recommending physical activity to adults with disabilities. Prev Chronic Dis 2017;14:E114.

56. Lobelo F, Rohm Young D, Sallis R, Garber MD, Billinger SA, Duperly J, et al. Routine assessment and promotion of physical activity in healthcare settings: a scientific statement from the American Heart Association. Circulation 2018;137:e495-522. 
57. Piercy KL, Troiano RP, Ballard RM, Carlson SA, Fulton JE, Galuska DA, et al. The physical activity guidelines for Americans. JAMA 2018;320:2020-8.

58. Mottola MF, Davenport MH, Ruchat SM, Davies GA, Poitras VJ, Gray CE, et al. 2019 Canadian guideline for physical activity throughout pregnancy. Br J Sports Med 2018;52:1339-46.

59. Choi BC, Pak AW, Choi JC, Choi EC. Daily step goal of 10,000 steps: a literature review. Clin Invest Med 2007;30:E146-51.

60. Wattanapisit A, Thanamee S. Evidence behind 10,000 steps walking. J Health Res 2017;31:241-8.

61. Tudor-Locke C, Bassett DR Jr. How many steps/day are enough?: preliminary pedometer indices for public health. Sports Med 2004; 34:1-8.

62. Tudor-Locke C, Aguiar EJ, Han H, Ducharme SW, Schuna JM Jr, Barreira TV, et al. Walking cadence (steps/min) and intensity in 2140year olds: CADENCE-adults. Int J Behav Nutr Phys Act 2019;16:8.

63. Tudor-Locke C, Han H, Aguiar EJ, Barreira TV, Schuna JM Jr, Kang M, et al. How fast is fast enough?: walking cadence (steps/min) as a practical estimate of intensity in adults: a narrative review. Br J Sports Med 2018;52:776-88.

64. Little RM, Paterson DH, Humphreys DA, Stathokostas L. A 12-month incidence of exercise-related injuries in previously sedentary community-dwelling older adults following an exercise intervention. BMJ Open 2013;3:e002831.

65. Morrow JR Jr, Defina LF, Leonard D, Trudelle-Jackson E, Custodio MA. Meeting physical activity guidelines and musculoskeletal injury: the WIN study. Med Sci Sports Exerc 2012;44:1986-92.

66. Reddy PR, Reinier K, Singh T, Mariani R, Gunson K, Jui J, et al. Physical activity as a trigger of sudden cardiac arrest: the Oregon Sudden Unexpected Death Study. Int J Cardiol 2009;131:345-9.

67. Powell KE, Heath GW, Kresnow MJ, Sacks JJ, Branche CM. Injury rates from walking, gardening, weightlifting, outdoor bicycling, and aerobics. Med Sci Sports Exerc 1998;30:1246-9.

68. Berdowski J, de Beus MF, Blom M, Bardai A, Bots ML, Doevendans PA, et al. Exercise-related out-of-hospital cardiac arrest in the general population: incidence and prognosis. Eur Heart J 2013;34:3616-23.

69. Edwards MJ, Fothergill RT. Exercise-related sudden cardiac arrest in London: incidence, survival and bystander response. Open Heart 2015;2:e000281.

70. Toukola TM, Kauppila JP, Pakanen L, Kortelainen ML, Martikainen M, Huikuri HV, et al. Characteristics and prognosis of exercise-related sudden cardiac arrest. Front Cardiovasc Med 2018;5:102.

71. Berdowski J, Berg RA, Tijssen JG, Koster RW. Global incidences of out-of-hospital cardiac arrest and survival rates: systematic review of 67 prospective studies. Resuscitation 2010;81:1479-87.

72. Dahabreh IJ, Paulus JK. Association of episodic physical and sexual activity with triggering of acute cardiac events: systematic review and meta-analysis. JAMA 2011;305:1225-33.

73. Franklin BA. Preventing exercise-related cardiovascular events: is a medical examination more urgent for physical activity or inactivity? Circulation 2014;129:1081-4.

74. Bredin SS, Gledhill N, Jamnik VK, Warburton DE. PAR-Q+ and ePARmed-X+: new risk stratification and physical activity clearance strategy for physicians and patients alike. Can Fam Physician 2013;59:2737.
75. Warburton DE, Gledhill N, Jamnik VK, Bredin SS, McKenzie DC, Stone J, et al. Evidence-based risk assessment and recommendations for physical activity clearance: consensus document 2011. Appl Physiol Nutr Metab 2011;36 Suppl 1:S266-98.

76. Riebe D, Franklin BA, Thompson PD, Garber CE, Whitfield GP, Magal $\mathrm{M}$, et al. Updating ACSM's recommendations for exercise preparticipation health screening. Med Sci Sports Exerc 2015;47:2473-9.

77. Joy EA, Pescatello LS. Pre-exercise screening: role of the primary care physician. Isr J Health Policy Res 2016;5:29.

78. Breckon JD, Johnston LH, Hutchison A. Physical activity counseling content and competency: a systematic review. J Phys Act Health 2008;5:398-417.

79. Aittasalo M, Kukkonen-Harjula K, Toropainen E, Rinne M, Tokola K, Vasankari T. Developing physical activity counselling in primary care through participatory action approach. BMC Fam Pract 2016;17:141.

80. Shuval K, Leonard T, Drope J, Katz DL, Patel AV, Maitin-Shepard M, et al. Physical activity counseling in primary care: insights from public health and behavioral economics. CA Cancer J Clin 2017;67:23344.

81. Prochaska JO, Velicer WF. The transtheoretical model of health behavior change. Am J Health Promot 1997;12:38-48.

82. Barisic A, Leatherdale ST, Kreiger N. Importance of frequency, intensity, time and type (FITT) in physical activity assessment for epidemiological research. Can J Public Health 2011;102:174-5.

83. O'Donovan G, Lee IM, Hamer M, Stamatakis E. Association of "weekend warrior" and other leisure time physical activity patterns with risks for all-cause, cardiovascular disease, and cancer mortality. JAMA Intern Med 2017;177:335-42.

84. Jamnik VK, Warburton DE, Makarski J, McKenzie DC, Shephard RJ, Stone JA, et al. Enhancing the effectiveness of clearance for physical activity participation: background and overall process. Appl Physiol Nutr Metab 2011;36 Suppl 1:S3-13.

85. Ainsworth BE, Haskell WL, Herrmann SD, Meckes N, Bassett DR Jr, Tudor-Locke C, et al. 2011 Compendium of Physical Activities: a second update of codes and MET values. Med Sci Sports Exerc 2011;43: 1575-81.

86. Burnet K, Kelsch E, Zieff G, Moore JB, Stoner L. How fitting is F.I.T.T?: a perspective on a transition from the sole use of frequency, intensity, time, and type in exercise prescription. Physiol Behav 2019;199:3334.

87. Tulloch H, Fortier M, Hogg W. Physical activity counseling in primary care: who has and who should be counseling? Patient Educ Couns 2006;64:6-20.

88. Rowley N, Mann S, Steele J, Horton E, Jimenez A. The effects of exercise referral schemes in the United Kingdom in those with cardiovascular, mental health, and musculoskeletal disorders: a preliminary systematic review. BMC Public Health 2018;18:949.

89. Williams NH, Hendry M, France B, Lewis R, Wilkinson C. Effectiveness of exercise-referral schemes to promote physical activity in adults: systematic review. Br J Gen Pract 2007;57:979-86.

90. Campbell F, Holmes M, Everson-Hock E, Davis S, Buckley Woods H, Anokye N, et al. A systematic review and economic evaluation of exercise referral schemes in primary care: a short report. Health Technol Assess 2015;19:1-110.

91. Dacey ML, Kennedy MA, Polak R, Phillips EM. Physical activity 
counseling in medical school education: a systematic review. Med Educ Online 2014;19:24325.

92. Wattanapisit A, Tuangratananon T, Thanamee S. Physical activity counseling in primary care and family medicine residency training: a systematic review. BMC Med Educ 2018;18:159.

93. Irving G, Neves AL, Dambha-Miller H, Oishi A, Tagashira H, Verho A, et al. International variations in primary care physician consultation time: a systematic review of 67 countries. BMJ Open 2017;7:e017902.

94. O'Brien M, Shields C, Crowell S, Theou O, McGrath P, Fowles J. The effects of previous educational training on physical activity counselling and exercise prescription practices among physicians across Nova Scotia: a cross-sectional study. Can Med Educ J 2018;9:e35-45.

95. Fowles JR, O'Brien MW, Solmundson K, Oh PI, Shields CA. Exercise is Medicine Canada physical activity counselling and exercise prescription training improves counselling, prescription, and referral practices among physicians across Canada. Appl Physiol Nutr Metab 2018;43:535-9.

96. Arsenijevic J, Groot W. Physical activity on prescription schemes
(PARS): do programme characteristics influence effectiveness?: results of a systematic review and meta-analyses. BMJ Open 2017;7: e012156.

97. Rodjer L, H Jonsdottir I, Borjesson M. Physical activity on prescription (PAP): self-reported physical activity and quality of life in a Swedish primary care population, 2-year follow-up. Scand J Prim Health Care 2016;34:443-52.

98. Sudore RL, Schillinger D. Interventions to improve care for patients with limited health literacy. J Clin Outcomes Manag 2009;16:20-9.

99. Public Health England; NHS England; Health Education England. Making Every Contact Count (MECC): consensus statement. London: Public Health England; 2016.

100. Son KY, Lee CM, Cho B, Lym YL, Oh SW, Chung W, et al. Effect of additional brief counselling after periodic health examination on motivation for health behavior change [corrected]. J Korean Med Sci 2012;27:1285-91.

101. Joy EL, Blair SN, McBride P, Sallis R. Physical activity counselling in sports medicine: a call to action. Br J Sports Med 2013;47:49-53. 